\title{
Effect of gluten-free flour on sensory, physico- chemical, structural and mechanical properties of wafer batter and waffles
}

\section{Victoria Dorohovych, Mariia Hrytsevich, Nataliia Isakova}

\author{
National University of food Technologies, Kyiv, Ukraine
}

Keywords:

Flour

Celiac

Gluten-free

Gluten

Waffles

\section{Article history:}

Received

13.05.2018

Received in revised

form 18.06.2018

Accepted 29.06.2018

Corresponding

author:

Mariia Hrytsevich

E-mail:

m.gricevich@

gmail.com

DOI:

$10.24263 / 2304-$

974X-2018-7-2-8

\section{Abstract}

Introduction. The research was carried out to determine the impact of different varieties of gluten-free flour on semifinished and finished wafer sheets.

Materials and methods. Materials: rice, corn, buckwheat flour, waffle batter and waffle sheets. Sedimentation of the dough was determined by measuring the column of the liquid; bound and free moisture - by the derivatization method, strength - by determining the force required for breaking the wafer sheet.

Results and discussion. Rational moisture content of dough with rice flour is 63 , buckwheat -80 , corn $-65 \%$.

The highest density has a dough with buckwheat flour 1,113 , corn $-1,083$, rice $-1,065 \mathrm{~g} / \mathrm{cm}^{3}$, the least with wheat $1,053 \mathrm{~g} / \mathrm{cm}^{3}$. This can be explained by different water absorption capacity of flour.

Sedimentation is maximal for dough with rice flour -25.2 , corn -15.1 , wheat $-10 \%$. Dough with buckwheat flour is not subject to sedimentation. This is due to the presence of cellulose and pentosans.

The dough of buckwheat flour has a maximum viscosity (25.3 Pa.s), minimum - with rice (4.97 Pa.s). Viscosity of the dough with wheat flour-corn $7.97 \mathrm{~Pa} \cdot \mathrm{s}$. It is substantiated by different chemical composition and different dispersion of wheat and gluten free types of flour, and is consistent with the content of free and bound moisture - for a test with buckwheat flour $56.04 \%$, with rice -35.97 .

The highest strength - wafer sheets with corn and wheat flour (4.9 $\mathrm{n}$ and 4.1 respectively). The highest sedimentation wheat and buckwheat flour (119.4 and $115.4 \%$ respectively), it is explained by different nutrient composition of all types of flour.

Calculations of the nutritional value showed that wafer sheet with buckwheat flour has bigger amount of proteins than the wafer sheets with rice and corn flour. Energy value of wafer sheets for different types of flour do not have much difference.

Conclusions. Gluten-free flour changes physico-chemical parameters of semi-finished and waffle sheets. 


\section{Introduction}

Celiac disease (gluten enteropathy) - a disease characterized by chronic inflammation of a mucosa of small intestine, accompanied by malabsorption and arises as a result of intolerance to gluten. Approximately $1 \%$ of the population of America, Europe and the Eastern Mediterranean; and about $0.33 \%$ of the population in Asia, Africa and Australia suffer from celiac disease [3].

Patients with celiac disease should follow a gluten-free diet for lifetime. This leads to a reduction of symptoms and restoration of normal activity of the intestine. Therefore, people with celiac disease need gluten-free food, and it becomes a real challenge for manufacturers, especially in bread, pastry and pasta making. [5] Gluten (a protein found in most cereals) plays a key technological role in baking quality characteristics, being responsible for water absorption capacity, cohesivity, viscosity, and elasticity of dough. [6]

A range of gluten free products have been developed using rice and corn flours, which are often combined with corn, potato, or cassava starches as base flours because they are widely available, inexpensive ingredients that are bland in taste and flavor [7], [8]. However, the assortment of gluten-free products remains very small, while the needs of the modern consumers are constantly growing. [8], [9]. There are a lot of scientific works on the and research of quality indicators and development of gluten-free bread with different types of gluten free flour, starches and hydrocolloids published in modern scientific magazines [12], [13], [14] while the issue of the and research of quality indicators and development of gluten free pastry requires additional researches.

Most of the time nutritional status and demands of celiac patients are not satisfactorily covered when formulation and production of gluten-free products is carried out [11]. It is expedient to develop and implement technology in the production of gluten-free flour confectionery products for people with celiac disease based on gluten-free types of flour, such as rice, corn, buckwheat.

Nowadays there is no conducted research on the impact of gluten-free flour on quality parameters of the batter and waffles. In particular, viscosity, density, sedimentation, water absorption, strength, free and bound moisture content, require additional research and scientific justification. The complexity of the technology of gluten-free flour confectionery is that gluten-free flour and different kinds of starches have other properties than wheat flours. Scientists should improve technologies of gluten-free products to achieve similar structural, mechanical and physicochemical characteristics of gluten free and traditional in semi-finished products. Consequently, these gluten-free products can be produced on existing equipment.

Among the variety of pastry products, products based on waffles occupy a significant place. Due to this fact the research and scientific justification of quality indicators of the batter and waffles with using of the gluten-free flour are essential.

The main aim and tasks of research are: determination and scientific justification of the influence of gluten-free flour on Sensory, physical-chemical and structure-mechanical properties of the batter and waffles which patients with celiac disease can consume; calculation of nutritional and energy values. 


\section{Materials and methods}

\section{Materials}

The technology of waffles based on gluten-free flour which patients with celiac disease can consume; rice, corn, buckwheat flour, waffle batter and waffle sheets based on different types of gluten-free flour. [1], [3], [17]

\section{Methods}

\section{Determination of density of waffle batter}

Picnometric method was used, which is based on measuring the mass of a certain volume of the product at a temperature from the following absolute and relative density [15].

\section{Determination of viscosity}

The rotational viscometer was used to determine the viscosity of the wafer batter [15].

\section{Determination of sedimentation}

Following method was used:50 $\mathrm{cm}^{3}$ of the wafer batter was poured into a glass and measured the height. The height of the column of liquid that formed above the test was measured every $30 \mathrm{~min}$ for $120 \mathrm{~min}$. The sedimentation rate is determined from the ratio of the height of the dough column to the height of the liquid column [17], [15].

\section{Determination of bound and free moisture}

The determination was performed by derivatograph Q-1500 [16]. The sample and the standard are loaded into the working volume and heated at a constant rate. The device measured the temperature of the sample and the difference between the temperature of the sample and the standard reference temperature difference, sample mass change, and the difference in masses of the reference and working samples. Samples are heated and at a rate of $1.25{ }^{\circ} \mathrm{C} / \mathrm{min}$ at the temperature range from 20 to $250{ }^{\circ} \mathrm{C}$. The recording device captures the graphs. Analysis of derivatograms was made [16]

\section{Determination of strength}

The strength was determined by method used for determination the strength of macaroni [18]. The wafer sheet was placed in the grooves of the walls of the device, which are attached to the pad of the dial scale. Pressed the "down" button, immediately after the sheet was broken clicked the "stop" and "up". The force by which the sheet was broken was determined by the arrow on the dial at the time of the break.

\section{Determination of water absorption}

To determine the absorption of water was used a bucket which consists of a bowl with a diameter of $90 \mathrm{~mm}$, a height of $30 \mathrm{~mm}$, cover and handle that can be removed. The bowl and cover have holes of $2 \mathrm{~mm}$ in size, the distance between them is 5-6 mm. Pieces of waffle sheet were placed in a bowl and weighed then the bowl was closed with a cover and lowered for 5 minutes into water with a temperature of 60 degrees Celsius. After that the cup was taken out of the water and weighed [15]. The coefficient of water absorption was determined from the ratio of the mass of wafer sheets before and after wetting [17]. 


\section{- Food Technology}

\section{Results and discussion}

\section{Sensory properties of the waffle dough}

The consistency of the dough was evaluated in the first phase of research. Firstly, the dough was made with a moisture content $67 \%$, which is rational to received quality wafer made of wheat flour under laboratory conditions. Established that there is a need to adjust the moisture content in the case of different types of gluten-free flour (Table 1).

Table 1

Sensory properties of waffle dough

\begin{tabular}{|l|c|l|}
\hline $\begin{array}{l}\text { Dough with the } \\
\text { addition of } \\
\text { flour }\end{array}$ & $\begin{array}{c}\text { Moisture } \\
\text { content, } \%\end{array}$ & \multicolumn{1}{c|}{ Characteristics of the dough } \\
\hline Wheat flour & 67 & $\begin{array}{l}\text { The dough has needed consistency, which enables the } \\
\text { formation of waffles }\end{array}$ \\
\hline \multirow{2}{*}{ Rice flour } & 67 & $\begin{array}{l}\text { Very liquid consistency, which is not typical for waffle } \\
\text { dough }\end{array}$ \\
\cline { 2 - 3 } Corn flour & 63 & The dough has needed consistency \\
\cline { 2 - 4 } & 67 & $\begin{array}{l}\text { The consistency of the dough is more liquid than the } \\
\text { dough from wheat flour. The dough separates quickly. }\end{array}$ \\
\hline \multirow{2}{*}{ Buckwheat flour } & 65 & $\begin{array}{l}\text { The dough has more dense consistency, which is close } \\
\text { to the wheat flour dough }\end{array}$ \\
\cline { 2 - 3 } & 80 & $\begin{array}{l}\text { The dough is thick, elastic and has not fluidity. } \\
\text { Formation waffles impossible by casting }\end{array}$ \\
\hline
\end{tabular}

The research found that rational moisture for the dough with rice flour is $63 \%$ with buckwheat flour $-80 \%$, with corn flour $-65 \%$.

Important indicators for the dough for wafers are density and resistance to separation (sedimentation).

\section{Density of the waffle dough}

The research on the density of waffle dough with gluten-free flour (Figure 1) showed that it is different from the density of wheat flour dough. 


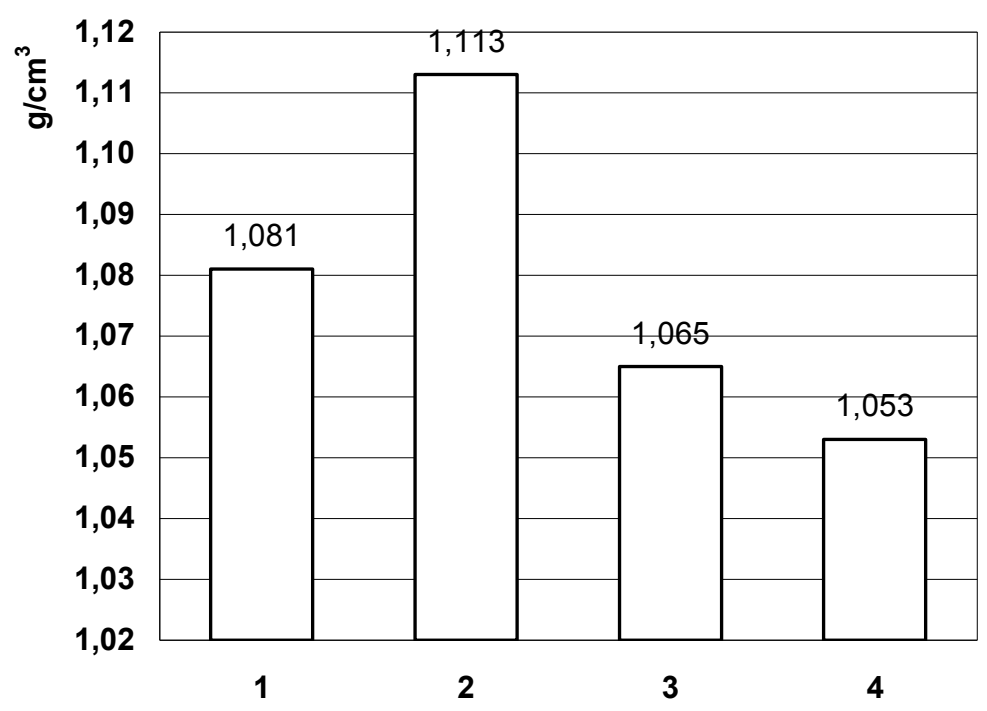

Figure 1. Density for waffle dough with using of different types of gluten-free flour for rational moisture content:

1 - Dough with corn flour;

2 - Dough with buckwheat flour;

3 - Dough with rice flour;

4 - Dough with wheat flour.

In the light of the results of the research on determination the density of waffle dough it can be concluded that the dough with buckwheat flour has the maximum density and the dough with rice flour has the minimum density. It can be associated with a water absorption capacity of flour: the dough with buckwheat flour has the maximum water absorption and the dough with rice flour has the minimum water absorption.

\section{Sedimentation of the waffle dough}

According to the technology of wafers production, after mixing in the dough mixer the dough does not fed to the formation simultaneously, and some time is in the intermediate tank. Therefore, an important technological aspect is the stability of the dough to the separation, i.e. sedimentation.

The research on the sedimentation of waffle dough with gluten-free flour (Figure 2) showed that it is different from sedimentation of dough with wheat flour. 


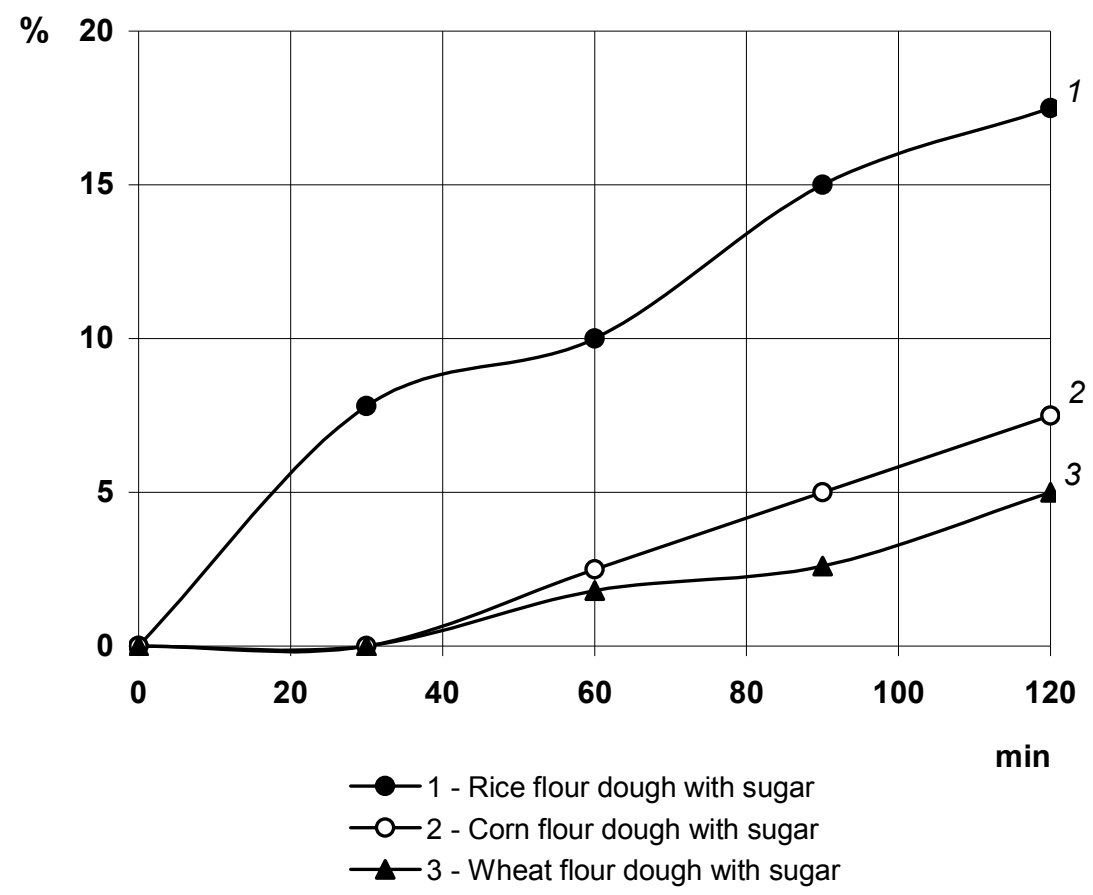

Figure 2. Sedimentation of waffle dough with gluten-free flour for the rational moisture content and with sugar

The dough with corn flour has the maximum sedimentation and the dough with buckwheat flour does not have sedimentation. This can be explained by large water absorption capacity of buckwheat flour, due to peculiarities of its chemical composition, including the presence of cellulose and pentosanes.

\section{Viscosity of the waffle dough}

The dough viscosity index is very important in the technology of waffles. It causes the accurate dosage of the dough during its filing in the form of wafer ovens and getting waffles with smooth edges.

The viscosity of the dough depends on the moisture content of the dough and the amount of free and bound water. Change of moisture content of the dough with wheat flour increases or decreases the thickness of the hydration shell around the particles of gluten. The thickness of the hydration shell around the particles of gluten increases with increasing of moisture content of the dough, aggregation decreases and consequently viscosity of the dough decreases. The thickness of hydration shell decreases with decreasing of moisture content of the dough, sustainability of the system with the formation of aggregates of particles of flour decreases. Accordingly, the viscosity of the dough increases.

There is need to create a rare mass with some viscosity indexes in the case making waffle dough. The research of viscosity of dough with gluten-free flours showed that the doughs with different types of flour and the dough with wheat flour have different viscosity indexes. 
However, in the case of manufacturing it at a certain rational moisture which is different for different types of dough with different gluten-free flour, it is within the range that allow to form product (Figure 3).

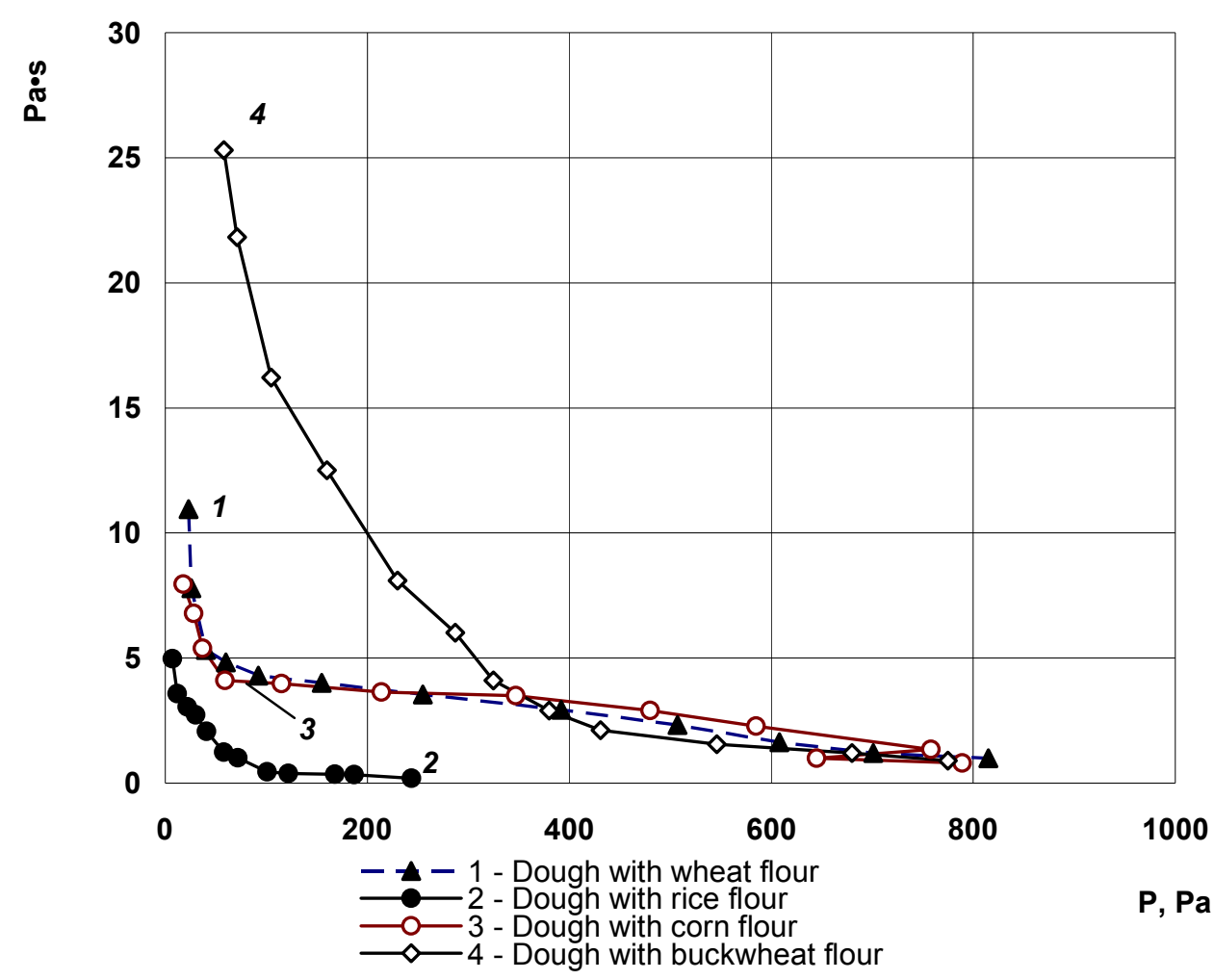

Figure 3. Viscosity of waffle dough with gluten-free flour for the rational moisture content

In the light of the results it can be conclude that the dough with buckwheat flour has the highest viscosity and the dough with rice flour has the lowest viscosity. Different viscosity of the doughs can be explained by the different moisture content of the doughs and different composition of wheat, rice, corn flour.

If we analyze the change of viscosity of the dough from one type of flour, depending on moisture content, it should be mentioned that the dough viscosity increases with decreasing of moisture content. The research that have been conducted found that the viscosity of waffle dough with rice flour on a $67 \%$ moisture content is $2.98 \mathrm{~Pa} \cdot \mathrm{s}$, and with $63 \%$ moisture content $-4.97 \mathrm{~Pa} \cdot \mathrm{s}$. At the same time moisture of dough with rice and corn flour are lower than with wheat flour; the viscosity indexes are also lower. Moisture content and viscosity of dough with buckwheat flour is higher than with wheat flour.

This is due to different chemical composition and dispersion of different types of gluten-free and wheat flour. So, buckwheat flour contains higher amounts of fiber, significant content of pentosane, which makes high ability to absorb water and causes an increase in viscosity. Rice flour contains less protein than corn, wheat and buckwheat flour. 
The viscosity of intact structures $\left(\eta_{0}\right)$, the viscosity of the destroyed structures $\left(\eta_{m}\right)$ and the range of variation of viscosity with increasing shear stress $\left(\eta_{0-m}\right)$ were calculated according to the viscosity curves (Table 2).

Table 2

Dependence of the of viscosity of waffle dough with gluten-free flour with sugar, $\mathrm{Pa} \cdot \mathrm{s}$

\begin{tabular}{|l|c|c|c|}
\hline \multirow{2}{*}{$\begin{array}{l}\text { The dough with the } \\
\text { addition of flour }\end{array}$} & $\mathbf{\eta}_{\mathbf{0}}$ & $\mathbf{\eta}_{\mathbf{m}}$ & $\mathbf{\eta}_{\mathbf{0}-\mathbf{m}}$ \\
\cline { 2 - 4 } & 10,95 & 0,36 & 10,59 \\
\hline Wheat flour & 4,97 & 0,18 & 4,79 \\
\hline Rice flour & 7,96 & 0,6 & 7,36 \\
\hline Corn flour & 25,3 & 0,57 & 24,73 \\
\hline Buckwheat flour & &
\end{tabular}

\section{Free and bound moisture}

As it has been noted before, the viscosity of dough also has affects the distribution of moisture in free and bound. Than smaller the amount of free moisture and more bound moisture, than higher the viscosity of the dough. The results of differential thermal studies found the number of free and bound moisture in the doughs with various kinds of glutenfree flour (Table 3).

Table 3

Calculation of free and bound moisture

\begin{tabular}{|l|c|c|c|c|c|c|}
\hline \multirow{2}{*}{$\begin{array}{l}\text { Dough with the } \\
\text { addition of flour }\end{array}$} & \multicolumn{2}{|c|}{ Total } & \multicolumn{2}{c|}{ Free } & \multicolumn{2}{c|}{ Bound } \\
\cline { 2 - 7 } & $\mathbf{m g}$ & $\mathbf{\%}$ & $\mathbf{M g}$ & $\mathbf{\%}$ & $\mathbf{m g}$ & \% \\
\cline { 2 - 7 } & 130,40 & 100 & 79,20 & 60,73 & 51,20 & 39,26 \\
\hline Wheat flour & 125,30 & 100 & 80,00 & 63,84 & 45,30 & 36,15 \\
\hline Rice flour & 131,20 & 100 & 84,00 & 64,02 & 47,20 & 35,97 \\
\hline Corn flour & 145,60 & 100 & 64,00 & 43,95 & 81,60 & 56,04 \\
\hline Buckwheat flour
\end{tabular}

Calculation of percentage of free and bound water showed (tab. 3) that the buckwheat flour dough has a lot of bound moisture, the rice dough - the less content of bound moisture. This is consistent with the results of the research of viscosity (Fig. 3): the maximum in the buckwheat flour dough and the minimum in the rice dough.

Sensory and physico-chemical properties are important parameters of quality of final products.

\section{Sensory characteristics of the waffles}

Waffles with different types of flour showed their differences (Table 4) due to the peculiarities of taste, smell and color flour. 
Sensory characteristics of waffles with different types of flour

\begin{tabular}{|l|l|l|}
\hline $\begin{array}{l}\text { Waffles with the } \\
\text { addition of flour }\end{array}$ & \multicolumn{1}{|c|}{$\begin{array}{c}\text { Name of the } \\
\text { index }\end{array}$} & \multicolumn{1}{|c|}{ Characteristics of the index } \\
\hline \multirow{3}{*}{ Wheat flour } & Taste & $\begin{array}{l}\text { Sweet, inherent for wafers, without foreign } \\
\text { tastes }\end{array}$ \\
\cline { 2 - 3 } & Smell & Inherent for wafers, without foreign smell \\
\cline { 2 - 3 } & Color & From light yellow to cream \\
\hline Rice flour & Taste & Sweet, inherent for wafers \\
\cline { 2 - 3 } & Smell & Inherent for wafers, without foreign smell \\
\cline { 2 - 3 } & Color & From white to light yellow \\
\hline Corn flour & Taste & Sweet, inherent for wafers \\
\cline { 2 - 3 } & Smell & Inherent for wafers, without foreign smell \\
\cline { 2 - 3 } & Color & $\begin{array}{l}\text { From white to light yellow, white on a } \\
\text { break }\end{array}$ \\
\hline Buckwheat flour & Taste & Sweet inherent for buckwheat flour \\
\cline { 2 - 3 } & Smell & Inherent for buckwheat flour \\
\cline { 2 - 3 } & Color & Brown \\
\hline
\end{tabular}

\section{Strength and water absorption of the waffles}

Strength and water absorption arethat physical and chemical properties, which in greatest degree characterize the final products. Research of these parameters for waffles which contain different types of gluten-free flour and waffles which contain wheat flour are different (Table 5).

Table 5

\section{Strength and water absorption of waffles with different types of flour}

\begin{tabular}{|l|c|c|}
\hline $\begin{array}{l}\text { The waffles with the } \\
\text { addition of flour }\end{array}$ & $\begin{array}{c}\text { Strength, } \\
\text { N }\end{array}$ & $\begin{array}{c}\text { Water absorption } \\
\text { \% }\end{array}$ \\
\hline Wheat flour & 4,1 & 119,4 \\
\hline Rice flour & 4,9 & 106,8 \\
\hline Corn flour & 2,5 & 107,3 \\
\hline Buckwheat flour & 2,7 & 115,4 \\
\hline
\end{tabular}

The wafer sheets made with corn and wheat flour has the biggest strength. The wafer sheets made with wheat and buckwheat flour has higherwater absorption, this is due to different compositionof all types of flour.

\section{Nutrition and energy value of the waffles}

Food including pastry largely characterizes by their nutritional and energy value. This information must necessarily be indicated on the packaging.

It should be noted that there are strict requirements for foods for people who suffer from celiac disease. Gluten concentration should not exceed $20 \mathrm{mg}$ per $1 \mathrm{~kg}$ in products that initially did not contain gluten and $200 \mathrm{mg} / \mathrm{kg}$ in the products of which gluten has been 
removed in the production process [8]. So, it requires careful control of raw materials and finished products for the presence of gluten.

Results of calculation of nutrition and energy value of products are shown in Table 6.

Table 6

Nutrition and energy value of waffles with different types of flour

\begin{tabular}{|l|c|c|c|}
\hline Nutrients & $\begin{array}{c}\text { Waffles with corn } \\
\text { flour }\end{array}$ & $\begin{array}{c}\text { Waffles with rice } \\
\text { flour }\end{array}$ & $\begin{array}{c}\text { Waffles with } \\
\text { buckwheat flour }\end{array}$ \\
\hline Proteins, \% & 12,26 & 9,37 & 12,53 \\
\hline Fats, \% $\%$ & 7,22 & 7,09 \\
\hline Carbohydras, \% & 7,17 & 12,61 & 15,86 \\
\hline Energy value, kcal & 13,17 & 319,22 & 338,06 \\
\hline
\end{tabular}

\section{Conclusions}

The moisture content of a dough in case of use rice and corn flour should be reduced compared to moisture of dough with wheat flour, in the case of use buckwheat flour it should be increased to obtain high quality waffles.

The dough with buckwheat flour has the maximum density and viscosity, the dough with rice flour has minimum. Maximum separation occurs in the dough with corn flour, the dough with buckwheat flour does not separate. This is due to the peculiarities of the chemical composition of different types of flour and their ability to absorb water, different moisture of dough, different contents of free and bound water in the dough.

Wafer sheets, especially with buckwheat and corn flour have certain characteristics of flavor and color, but do not adversely effect on the Sensory characteristics.

Wafer sheet with buckwheat flour has bigger amount of proteins than wafer sheets with rice and corn flour. Energy value of wafer sheets for different types of flour do not have significant difference.

\section{References}

1. New technology for the production of gluten-free bakery products (2008), Food Technologies \& Equipment, 7, p. 9.

2. Van der Windt, Daniëlle A. W. M. et al., (2010), Diagnostic Testing for Celiac Disease Among Patients With Abdominal Symptoms, Journal of the American Medical Association, 6(306), p. 639.

3. Piezak M. (2012), Celiac disease, wheat allergy, and gluten sensitivity: When gluten free is not a fad, JPEN J Parental Enterol Nutr, 36(1), pp. 68S-75S.

4. Celiac disease (gluten enteropathy): [Electronic resource], Avilable at: http://webmed.com.ua/ua/zdorove_ot_a_do_ya/zabolevaniya/organy_picshevareni y/celiakiya_glyutenovaya_enteropatiya.

5. Capriles V.D., Santos F.G., Reis E.M., Pereira C.F. (2015), Innovative approaches to improve nutritional and bioactive compounds of grain-based gluten-free products, In: Langdon, R.(Ed.), Gluten-free diets: Food sources, role in celiac disease and health benefits, NovaSciencePublishers, NewYork:, pp. 67-116. 
6. Wieser H. (2007), Chemistry of gluten proteins, Food Microbiol., 24(2), pp. 115119

7. do Nascimento A., Fiates G., dos Anjos A., Teixeira E. (2013), Analysis of ingredient lists of commercially available gluten-free and gluten-containing food products using the text mining technique, International Journal of Food Sciences and Nutrition, 64, pp. 217-222.

8. PauceanA., Man S., Muste S., Pop A, (2016), Development of gluten free cookies from rice and coconut flour blends, Bulletin of University of Agricultural Sciences and Veterinary Medicine Cluj-Napoca: Food Science and Technology, 73(2), pp. 163-164.

9. Thompson T., Dennis M., Higgins L., Lee A., Sharrett M. (2005), Gluten-free diet survey: Are Americans with coeliac disease consuming recommended amounts of fibre, iron, calcium and grain foods?, Journal of Human Nutrition and Dietetics, 18 , pp. $163-169$.

10. Winger M., Khouryieh H., Aramouni F., Herald, T. (2014), Sorghum Flour Characterization and Evaluation in Gluten-Free Flour Tortilla, Journal of Food Quality, 37, pp. 95-106

11. Rosell C.M., Matos, M.E. (2015), Market and Nutrition Issues of Gluten-Free Foodstuff, In: Arranz E., Fernández-Bañares F., Rosell C.M., Rodrigo L. and Peña A.S., Eds., Advances in the Understanding of Gluten Related Pathology and the Evolution of Gluten-Free Foods, Omnia Science, Barcelona, pp. 675-713

12. Masure H.G., Fierens E. Delcour J., (2016) Current and forward looking experimental approaches in gluten-free bread making research, Journal of Cereal Science, 67, pp. 92-111.

13. Naqasha F., Ganib A., Gania A., Masoodia F.A., (2017), Gluten-free baking: Combating the challenges - A review, Trends in Food Science \& Technology, 66, pp. 98-107.

14. Sandri L., Santos F., Fratelli C., Capriles V., (2017), Development of gluten-free bread formulations containing whole chia flour with acceptable sensory properties, Food Science \& Nutrition, 5(5), pp. 1021-1028.

15. Romeo T. Toledo (2007), Fundamentals of Food Process Engineering, Springer Science \& Business Media, p. 570.

16. Pelovski Y., Petkova V., Nikolov S., (1996), Study of the mechanism of the thermochemical decomposition of ferrous sulphate monohydrate, Thermochimica Acta, 274, pp. 273-280

17. Karl F. Tiefenbacher (2017), Wafer and Waffle. Processing and Manufacturing, Acfdemic Press, p. 698.

18. A.Marti A., D'Egidio M.G., Pagani M.A., (2016), Pasta: Quality Testing Methods, Encyclopedia of Food Grains (Second Edition), 3, pp. 161-165. 